\title{
MAIN DESIGN FACTORS FOR SHARED RIDE-HAILING SERVICES FROM A USER PERSPECTIVE
}

\author{
M. GILIBERT ${ }^{1,2} \&$ I. RIBAS \\ ${ }^{1}$ Departament d'Organització d'Empreses (DOE), Universitat Politècnica de Catalunya BarcelonaTech (UPC), \\ Spain. \\ ${ }^{2}$ SEAT, S.A., Spain
}

\begin{abstract}
Shared ride-hailing transportation is discreetly emerging in cities all over the world with the purpose of decongesting cities, offering a similar comfort and convenience of the private car, and this way, filling the gap between the cities' bus services and the regular taxi services. Hence, the aim of this research is to detect the main factors that should be taken into account for the service design of shared ridehailing transportation, as well as to compare this mean of transport with the bus and taxi services. The research was conducted through, first, an analysis of shared ride-hailing services business model. Then, a quantitative research was conducted to users of a small-scale one-week pilot in Barcelona. The results show that factors related to price and travel times are more important from a user perspective than the ones related to comfort, such as the walking distance to the pickup point or the comfort provided by the vehicle. Furthermore, results indicate the intended use of participants of a potential future shared ride-hailing service in different use cases.

Keywords: Business Model Canvas, Mobility as a Service (MaaS), on-demand transport, ride-hailing, ridesharing, ride-sourcing, urban mobility.
\end{abstract}

\section{INTRODUCTION}

The trend towards a more sustainable urban mobility is growing, since both governments and citizens are giving more importance, day by day, to the environmental problems caused by urban mobility. At the same time, new transport means, such as on-demand shared mobility services, which are expected to be more sustainable than private vehicles, are becoming more popular, in particular, ride-hailing services. They operate like taxis, with the difference being that they are not authorised to pick up street hails and, therefore, require passengers to previously book their trips. This type of services are growing as an alternative to taxis, offering flexible and low-cost on-demand rides in an easy way and a better user experience [1]-[4]. Some examples are Cabify, Uber and Lyft. In addition, some ride-hailing services also offer the option of sharing the trips with other users. This option is known as shared ride-hailing. For instance, Via provides this type of service, and also Lyft and Uber under the options of Lyft Line and uberPOOL, respectively.

Shared ride-hailing services involve having, apart from the user application and the booking platform, matching and routing algorithms in order to group users who are going in the same direction, since a single journey may comprise many different pick-up and drop-off locations, involving many short detours.

Services providing shared rides prove to be more efficient than the current taxi services and the singular ride-hailing options. A recent study stated that $22 \%$ of the current taxi fleet of New York City could cover $98 \%$ of its taxi demand if rides were shared [5]. Besides, they are more flexible than bus services, since they can easily reach areas that are not covered by the public transport or that are inefficiently covered, e.g. low service frequency. On the other hand, some public transport operators are beginning to transform their traditionally scheduled bus services into on-demand services, thus offering a more efficient and suitable 
public transport to, for example, commute. This is the case of the Oxford bus company, which provides a demand-responsive bus service (PickMeUp) to improve the public transport offer in the Eastern Arc around Oxford [6].

Being shared ride-hailing services an opportunity to help decongesting cities, In Barcelona, where transport problems are increasing and some restrictions have already been announced to improve sustainability [7], a small-scale one-week shared ride-hailing pilot launched by CARNET (a future mobility research hub, part of the Volkswagen research network) was conducted in April 2017. Within the metropolitan region of Barcelona, the private vehicle is the first option to commute (19.2\% more in relation to public transport). By contrast, when traveling for personal reasons, citizens walk or cycle, secondly they use the private vehicle, and thirdly public transport (the use of the private vehicle being $17.2 \%$ greater than the use of public transport) [8]. In addition, on a working day, more than one million vehicles enter and leave the city of Barcelona [9]. The main reason for the greater use of private vehicles to commute is that some citizens do not have the option of public transport to cover their journeys, or if there is one, it does not offer a convenient frequency of service [10].

The aim of this study is, on one hand, to detect important factors that should be taken into account for the service design of shared ride-hailing services and, on the other hand, to compare shared ride-hailing transportation with the bus and taxi services. The importance of this research is based on the fact that if these services fail to convince private car users to use them, instead of helping to reduce the number of cars on the streets, they will bring more.

The rest of the article is organised as follows: the second section explains the methodology used to conduct the research process. In the third section, the main characteristics of the shared ride-hailing business model are reviewed. The fourth section presents the case study and the results. Finally, a discussion about the conducted research and the conclusions are provided.

\section{METHODOLOGY}

First, to understand the business model of shared ride-hailing services, and detect the main factors to take into account for the service design, a literature review was conducted through the electronic databases SCOPUS and Web of Science. Besides, to complete the information, we interviewed users and drivers of the uberPOOL service (four users and one driver) and CleverShuttle service (three users and one driver) and looked into the websites of other representative services, such as Via, Lyft Line and DiDi [11]-[15]. The information obtained was analysed using the methodology of Business Model Canvas (BMC) [16], which provides a clear overview of the business functions.

Next, the case study methodology [17] was used to design and analyse the small-scale 1-week pilot conducted in Barcelona. This pilot enabled us, through a survey, to compare the shared ride-hailing service provided with the bus and taxi services and to identify the most valued service factors from a user perspective. The questionnaire applied was structured in three sections. The first section asked the following demographic information and mobility patterns (classification questions): gender, age, employment status, if they had a driving license and a car or a scooter at their disposal, if they were intermodal commuters (use of more than one mean of transport to reach the destination) and which means of transport did they usually use to commute. The second section aimed to find out, using a 7-point rating scale, first, users' perception of specific aspects of the service, based on 
their experience during the pilot phase, and second, their expectations and requirements as users facing a possible future introduction of the service. Thus, participants valued the importance of eight service design factors: price of the service, distance to the pickup point, waiting time (notified when requesting the trip by the app), travel time, the fact of sharing the trip, comfort, and punctuality of the arrival of the vehicle at the pickup point and arriving at the destination. Besides, participants compared the shared ride-hailing service tried with the bus and taxi services. Finally, in the third section it was requested to assess the importance of general service factors, to select in which use cases they would use this type of transport (multiple choice question), and indicate how the price of the service should be calculated (closed-ended question). Participants were requested to answer the online survey after the pilot.

\section{SHARED RIDE-HAILING BUSINESS MODEL}

The analysis of the shared ride-hailing business model has been conducted by means of the BMC. The information obtained from the literature review was complemented with information from the services' websites and face-to-face interviews. From this analysis, we found that shared ride-hailing would be a recommended service for regular urban uses. In addition, we identified that, in many cases, the customer segment targeted is urban commuters. For instance, Via accepts payments from commuter benefits debit cards. Besides, Uber, in countries like Saudi Arabia, offers a reliable transport for women which enables them to keep their jobs [18]. The value proposition of shared ride-hailing services is to offer low-cost ondemand shared rides, of easy access and payment [1]-[4]. The main channels used to reach customers are the user app and the website as well as marketing actions, and the customer relationships are usually managed by an app-based reputation system and the customer service [19]. Regarding the revenue streams, this type of transportation is offered through pay per use, but with different combinations depending on the operator. This way, whereas uberPOOL charges a rate per mile or $\mathrm{km}$ and minute plus the surge pricing, Via offers a fixed price for the whole area covered. On the other hand, peer-to-peer (P2P) services such as uberPOOL or Lyft Line charge a commission per trip to their drivers. The main key resources are the vehicles (owned by the operator or by the freelance drivers), skilled drivers, the application for the users to request the rides, the application for the drivers to accept the rides and see the route to follow and the routing and matching algorithms, which enable the service to be shared by different users travelling to the same direction. Besides, the main key activities are the development of the technological system, the fleet operation and management and the maintenance of the vehicles, as well as conducting marketing actions to attract not only users but also drivers. As key partnerships we identified local governments and transport authorities, ICT and digital payment platform providers, geolocation services, and insurance companies [2], [4], in addition to freelance drivers in case of the P2P model. The main costs of the cost structure are the personnel, the acquisition and maintenance of the vehicle fleet, the development of the apps, algorithms and platforms, R\&D and marketing activities and the cost of infrastructure. Figure 1 presents the BMC with the key features of each building block of the shared ride-hailing business model.

\section{CASE STUDY}

The pilot analysed took place from the 24 to the 28 April 2017 with the participation of 67 volunteers, who used the service to commute from the city centre of Barcelona (example district) to the most western district of the city (Les Corts), as shown in Figure 2. Participants 


\begin{tabular}{|c|c|c|c|c|}
\hline \multirow[t]{2}{*}{$\begin{array}{ll}\text { Key Partnerships } \\
\text { - } & \text { Local governments } \\
\text { - } & \text { ICT platform } \\
& \text { providers } \\
\text { - } & \text { Payment operators } \\
\text { - } & \text { Providers of geo- } \\
& \text { localization services } \\
\text { - } & \text { Insurance companies } \\
\text { - } & \text { Freelance drivers } \\
& \text { (P2P) }\end{array}$} & $\begin{array}{l}\text { Key Activities } \\
\text { - Development of } \\
\text { the tech system } \\
\text { Operate and } \\
\text { manage the fleet } \\
\text { Vehicle } \\
\text { maintenance } \\
\text { Marketing }\end{array}$ & \multirow[t]{2}{*}{ 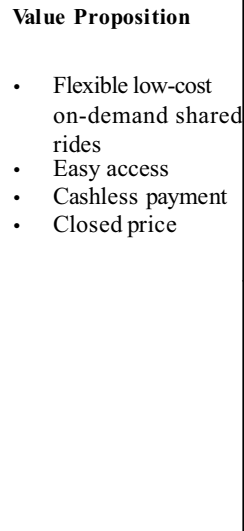 } & 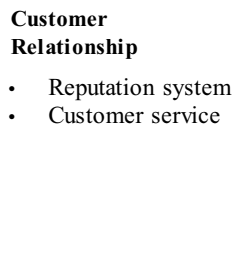 & \multirow[t]{2}{*}{$\begin{array}{l}\text { Customer Segments } \\
\text { - Urban regular users } \\
\text { - Commuters }\end{array}$} \\
\hline & 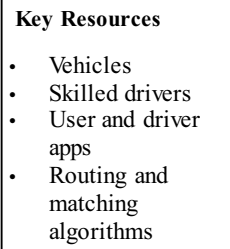 & & 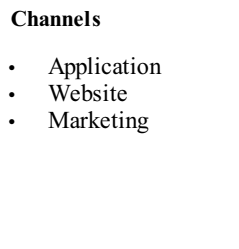 & \\
\hline \multicolumn{2}{|c|}{ 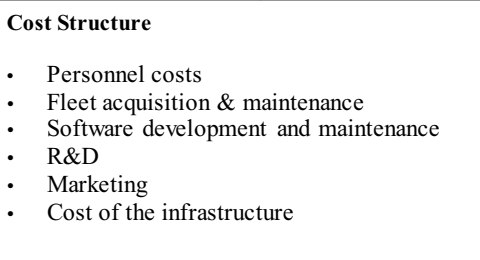 } & \multicolumn{3}{|c|}{$\begin{array}{l}\text { Revenue Streams } \\
\text { - Usage fee per ride: rate per mile or km and/or per min, flat } \\
\text { rates } \\
\text { - Platform commission per ride (P2P model) }\end{array}$} \\
\hline
\end{tabular}

Figure 1: Business Model Canvas of current shared ride-hailing services.

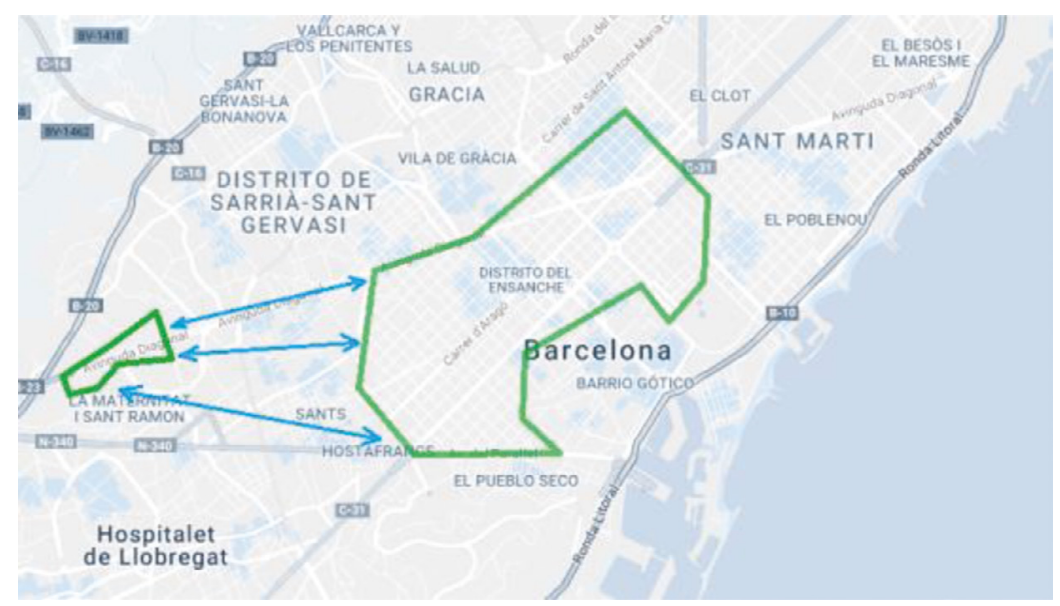

Figure 2: Map of the working area of the pilot.

willing to participate had to fill out an online request form, the link of which was distributed to students and employees from Universitat Politècnica de Catalunya (UPC) and employees from RACC (the largest car club in Spain, located next to the UPC campus). Both organisations collaborated in this way with the study. The rides had no cost and could be requested from 7 to 10 a.m. and from 4 to 8 p.m. The vehicles used were 10 black SEAT Alhambra, with 
a seating capacity of 4 people plus the driver. In addition to volunteers' requests, the system also received virtual requests based on a real demand pattern. This way, the service attempted to resemble reality as close as possible, which implied, among other topics, that real users had to wait for the service as in a real situation, as well as experience the vehicle detours to pick-up or drop-off other users, either virtual or real.

Participants were asked to first download the application provided by the start-up Shotl (on-demand bus technological platform provider) for the on-demand pickup requests; then, to use the service every day of the week; and, after the pilot week, to answer an online survey, which was completed by 55 participants. To request a ride, users had to specify the trip origin and destination - within the covered areas - and the number of people travelling with them. Then, the app showed the pickup time and location, the estimated time of the arrival and the drop-off site. Due to the service not being door-to-door, the pick-up and drop-off spots were between 100 and $400 \mathrm{~m}$ far from the addresses specified by the users.

\subsection{Participants' profile}

The respondents profile is described in Table 1. Most of the participants were under the age of $45(85.5 \%)$, were employed $(72.7 \%)$, had a driving license $(85.5 \%)$ and had access to a $\operatorname{car}(51 \%)$.

Concerning participants' mobility patterns to commute, most of them commuted by public transport (67.3\%), using mainly the metro and the bus, since the areas covered had a good public transport service, as shown in Figure 3. Besides, half of these users stated that they need to use more than one means of transport to reach their destinations.

Table 1: Respondents' profile.

\begin{tabular}{|c|c|c|}
\hline Question & Stated answers & Number of responses \\
\hline \multirow[t]{2}{*}{ Gender } & Men & 32 \\
\hline & Women & 23 \\
\hline \multirow[t]{4}{*}{ Age (years) } & $18-29$ & 27 \\
\hline & $30-45$ & 20 \\
\hline & $46-55$ & 7 \\
\hline & $55+$ & 1 \\
\hline \multirow[t]{2}{*}{ Driving license } & Yes & 47 \\
\hline & No & 8 \\
\hline \multirow[t]{2}{*}{ Car at disposal } & Yes & 28 \\
\hline & No & 27 \\
\hline \multirow[t]{2}{*}{ Motorcycle at disposal } & Yes & 15 \\
\hline & No & 40 \\
\hline \multirow[t]{2}{*}{ Occupation } & Employed & 40 \\
\hline & Student & 15 \\
\hline
\end{tabular}




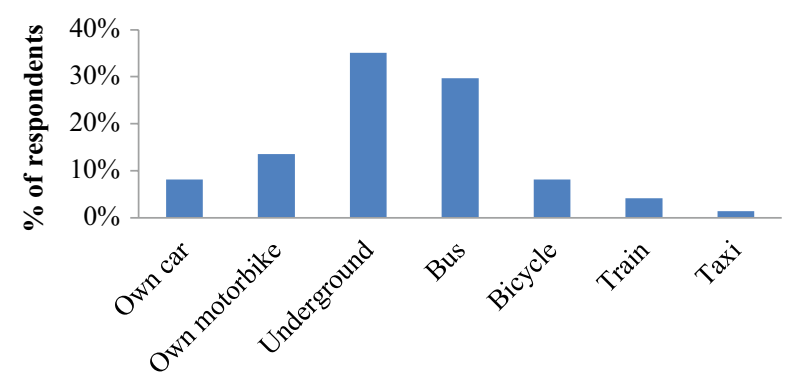

Mean of transport

Figure 3: Participants' commuting mean of transport.

\subsection{Service design factors}

Shared ride-hailing services are considered a means of transport between the bus and the taxi. Therefore, it is interesting to analyse relevant design factors and to detect how the users see the service in comparison with these other two means of transport. Accordingly, we analysed their opinion related to eight design factors: price of service, distance to pickup points, waiting time, punctuality of the arrival of the vehicle at the pickup point, travel time, the fact of sharing the trip, comfort, and punctuality arriving at the destination. From these factors, we found that the most important one from users' perspective when it comes to become a regular user of a shared ride-hailing service was the price, followed by the fact of not having transfers, the speed of the trip and the comfort of the vehicle (Figure 4).

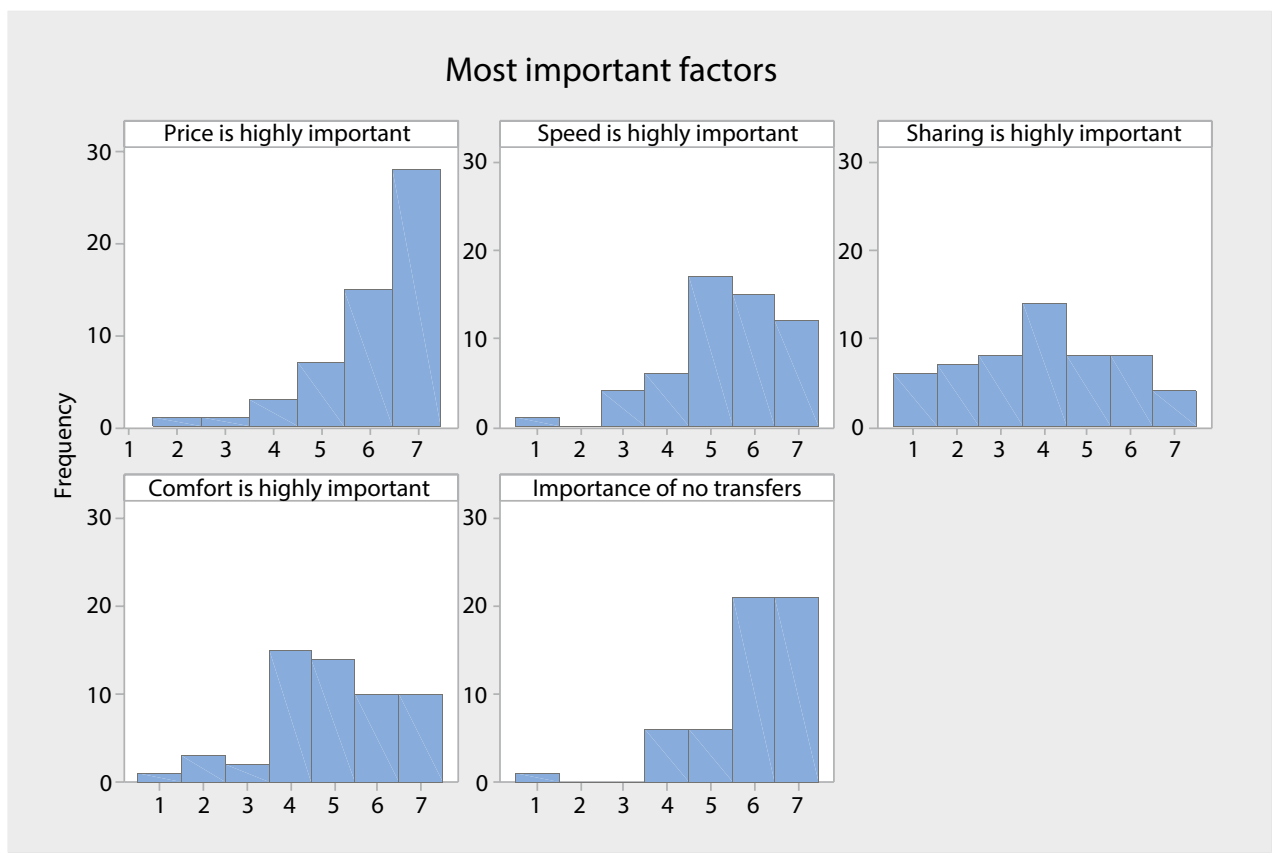

Figure 4: Histogram of importance of price, speed, sharing, comfort and no transfers [20]. 
Concerning the price factor, participants did not agree on one option to establish the price. $38.9 \%$ would prefer having a flat rate to travel within the city, whereas $33.3 \%$ would prefer that the price was related to the distance of the straightest path and the remaining $27.8 \%$ to the travel time on the fastest way. In addition, $72.7 \%$ of participants specified that their use would be higher if they had a loyalty card and $81.8 \%$ would increase their use if the payment method could be the same as the public transport. Figure 5 shows the frequency of answers related to price calculation. It is worth noting that only $30.9 \%$ of participants would pay up to 3.5 euro per trip, whereas only $12.7 \%$ would agree on paying 4.5 euro. Although the willingness to pay even a higher price could be higher in other areas and for other use cases, such as travelling within suburban areas or for night uses. Besides, the trips offered in this pilot were between 4 and $7 \mathrm{~km}$ long. For such trips, a taxi would charge, on average, from 8 to 12 euro. On the other hand, public transport would cost 2.20 euro if travelling with a single ticket, or less than 1.20 euro if travelling with a multi-journal ticket. Therefore, this factor can be critical to design a successful service, and especially, if the areas covered had a good public transport service.

Related to the distance to pickup points, $85.5 \%$ of participants would be willing to walk up to $5 \mathrm{~min}$ to the pickup point, whereas only $27.3 \%$ would walk up to $10 \mathrm{~min}$. On the other hand, $25.5 \%$ of participants would pay more than the fixed rate for a closer pickup. As stated before, the pilot service picked up and dropped off users from 100 to $400 \mathrm{~m}$ far from their origins and destinations. This distance was considered shorter compared to the regular bus by $54.5 \%$ of participants. In Barcelona, bus stops and metro stations are separated by a distance of 400 to $600 \mathrm{~m}$, approximately. Therefore, the distances considered in the pilot were adequate.

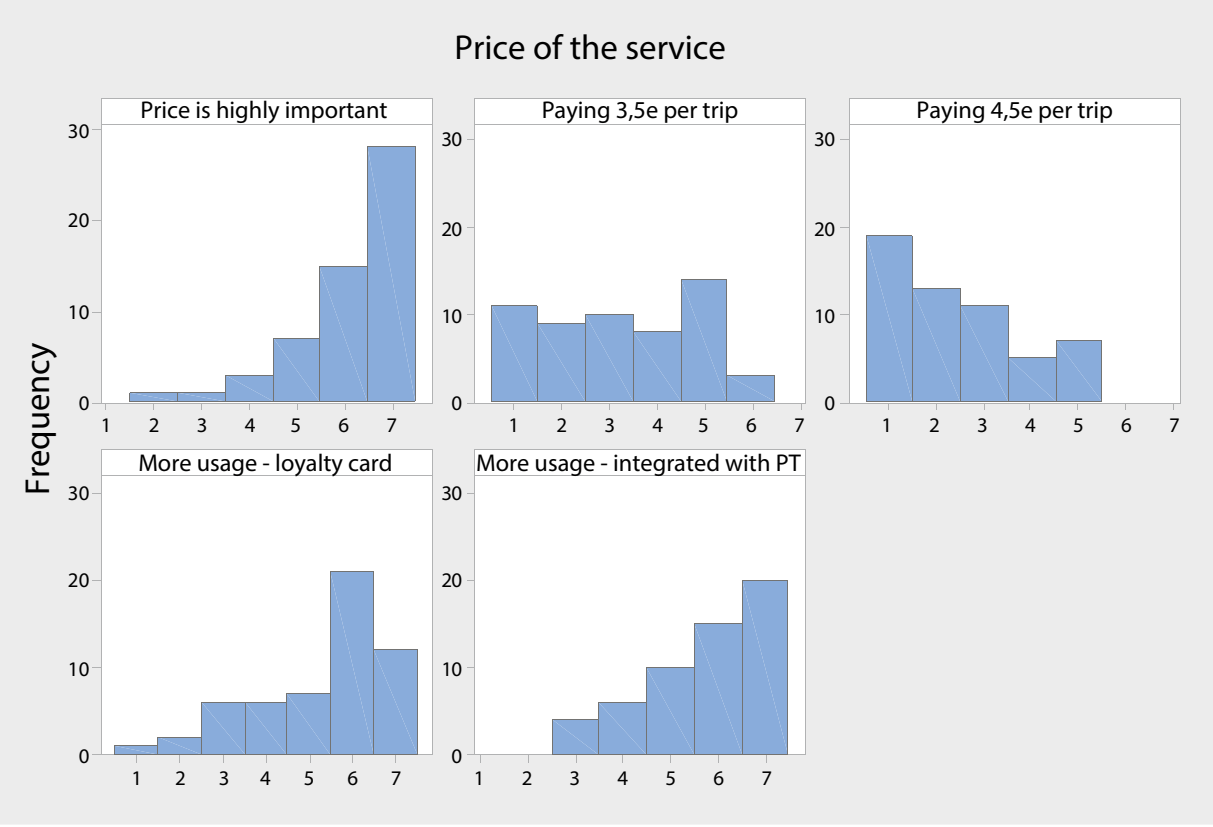

Figure 5: Histogram of different service characteristics related to the price definition. 
On the other hand, $51 \%$ of participants would not mind waiting up to $10 \mathrm{~min}$ for being picked up. Besides, $32.7 \%$ would pay more than the fixed rate for a shorter waiting time. By comparing the waiting time of the pilot service (time notified when requesting the service of the arrival of the vehicle) with the bus and taxi services, we saw that, although in the area covered by this pilot, the public transport service frequency was very high and, therefore, our participants were not used to wait more than 5-10 min, about $43.6 \%$ of participants considered that the waiting time of the pilot service was shorter compared to the usual waiting time of the bus, whereas $23.6 \%$ considered it shorter compared to the waiting time of the taxi service. This way, pilot results indicate that waiting up to $10 \mathrm{~min}$ for trips within the city would be accepted, and higher waiting times might also be accepted for trips out of the city centre, where public transport is not so convenient.

Moreover, $70.9 \%$ of users would accept a delay on the arrival of the vehicle if they would reach the destination on time; whereas $43.6 \%$ of users would accept up to 10 min-delay involving arriving late at the destination. However, this percentage rises to $83.6 \%$ if users would receive an economic compensation (e.g. free trip). In this case, $40 \%$ of users considered that the pilot service was more punctual than the bus; whereas $34.5 \%$ agreed on that it was more punctual than the taxi. Although punctuality of the pilot service had room for improvement, the results indicate that non-recurrent short delays would be accepted.

Regarding the travel time, $47.3 \%$ of users would pay a higher price if the service was faster. Although the speed of the vehicles was similar to the average speed of the bus service in Barcelona, since these vehicles could not use the bus lanes, $65.5 \%$ of participants considered that, once inside the vehicle, the pilot service was faster compared to the regular bus. In contrast, only $16.4 \%$ of participants considered that it was faster than the taxi service. Because this was a shared service, rides did not go direct to the destination and involved short detours and also short stops, so that other riders could get picked up and dropped off.

It is worth noting that sharing the ride in order to meet other users was not so important for the participants. This way, $29.1 \%$ of participants would pay a higher price if rides would be shared with less people. Thus, $74.5 \%$ of participants liked to share the rides with fewer people in comparison to the bus service.

The fact of not having to transfer is more important for users than the comfort of the vehicle used, $87.3 \%$ and $61.2 \%$, respectively. Though, they appreciated the comfort provided by the vehicles used for the pilot. $89.1 \%$ of users rated the comfort of these vehicles better than that offered by the bus service, and $54 \%$ rated it better than that offered by the taxi service.

Finally, $89.1 \%$ of users would not mind a delay of less than $5 \mathrm{~min}$ in arriving at the destination. However, only $47.3 \%$ of users would accept a delay of 5 to 10 min. Besides, if arriving with delay was compensated with the amount paid, $72.7 \%$ would accept a delay up to $5 \mathrm{~min}$ and $61.8 \%$ of up to $10 \mathrm{~min}$.

\subsection{General service characteristics}

In this section, the importance of general service characteristics, some related to the service and others related to the car design, are analysed. We found out that the most important service characteristics from participants' point of view were reliability, availability, safety and cleanliness of the vehicle. Notice that, in Figure 6, these four factors have a high score and small deviation. Besides, the integration of the service with other means of transport was also 


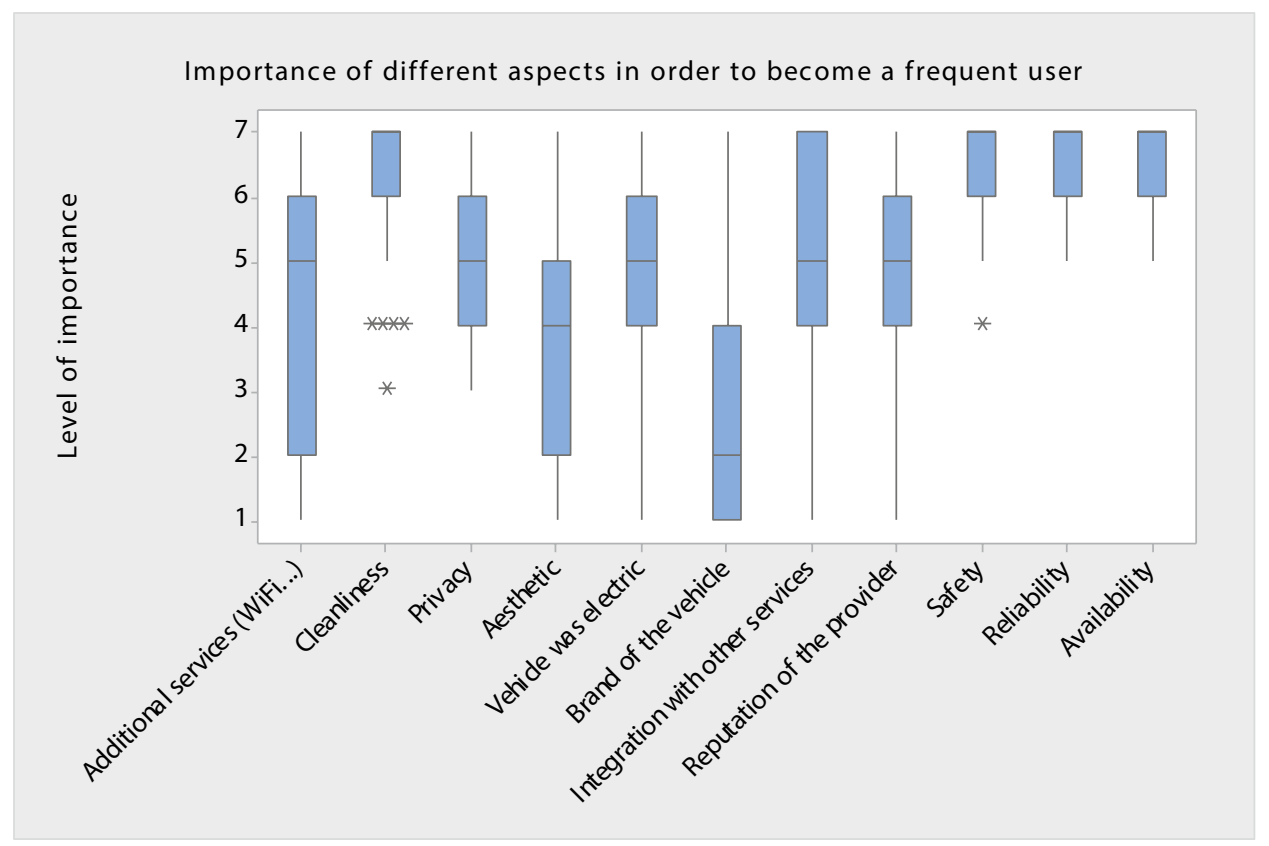

Figure 6: Boxplot of the importance of service factors to become a frequent user of the service [20].

seen critical. Users would like to use the integrated transport ticket of public transport to also pay the trips of shared ride-hailing services. This type of tickets enables users to also be able to transfer between the different city transport services paying only once.

Other characteristics with less score but also considered important were privacy issues, the reputation of the service provider and the fact that the vehicle was electric (vehicles used were not electric). On the other hand, the least important features for users were the brand of the vehicle, its design (aesthetic) and additional services such as Wi-Fi or having magazines to read on board.

\subsection{Use cases}

The pilot service connected two areas of the city of Barcelona during the commuting hours; therefore, participants used the service, mainly, to commute to work or to the university. Accordingly, the most voted use case was that of commuting (70.91\%). This would therefore confirm that this mobility service could be a suitable mean of transport for this type of trips. Besides, $67.27 \%$ of participants would also use it for leisure trips, such as going to the gym, going out to dinner or to parties; $50.91 \%$ for business trips and $47.27 \%$ to visit the doctor or go to the hospital. Shopping (either for groceries or not so regular purchases) and usual trips with family, such as picking up children at school, reached a lower intention of use. Figure 7 shows participants' intention of use for each use case. 


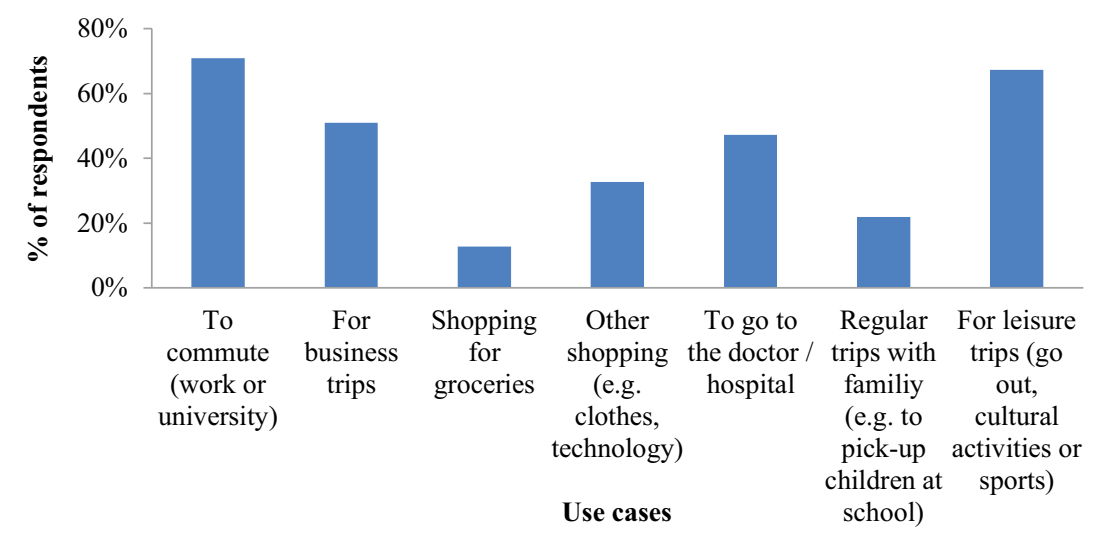

Figure 7: Intention of use of a shared ride-hailing service in different use cases.

\section{DISCUSSION AND CONCLUSION}

Shared ride-hailing services could be attractive transport alternatives for private car users (as they approach the quality offered by the private vehicles) and also for cities, since they would help relieve congestion if private car users became users of this type of services. But this type of transportation is quite new; therefore, the need for identifying the main service design factors that would make this mean of transport convenient for both users and cities is necessary. This way, from the pilot conducted in Barcelona, we detected the importance of setting a good pricing, which has a direct effect on the revenue streams. Users would not pay more than the double of the price of the bus or the subway for a daily commute within the city. Then, if these customer segments were targeted, the low price they would be willing to pay could complicate the profitability of the service. However, other use cases were identified, for which these customers might be willing to pay more, such as leisure or business trips.

On the other hand, shared ride-hailing services could cover the gap between the bus and taxi services, thus offering shared trips like the bus but with the convenience and comfort of the taxi. From the comparison of the service piloted with these two other means of transport, we identified that a shared ride-hailing service should offer shorter waiting times and a better punctuality in comparison to the public transport, although for achieving that in city centres, it might imply having a big vehicle fleet and optimised algorithms. In terms of the BMC, this research suggests that shared ride-hailing services should target different customer segments to be as cost-effective as possible, especially, intermodal users and citizens travelling from, within or to remoter areas. Concerning the value proposition, the application should offer an accurate estimation of the waiting and travel times as well as the estimated time of arrival at destination. Apart from that, the service should guarantee availability at all times and be reliable and safe. Regarding the vehicles used to provide the service, users' main concern was that they were clean. Key partnerships may include partnerships with transport authorities and operators, in order to discuss potential integrations within the fare systems, as well as subsidies to cover interurban and remote areas in a more efficient way than the regular scheduled buses, or even night services.

Although this study was based on a small-scale 1-week pilot, some preliminary conclusions could be stated. Further research should confirm these results conducting a more detailed study of the design factors with a larger user base. Furthermore, future studies should also 
address the impact that these new mobility services will have on urban traffic. They could be helpful for cities if they succeed in being a real alternative to the private car. Nevertheless, the risk of these services substituting public transport rides, and, therefore, adding more cars to the streets, should be assessed. Likewise, the analysis of the impact of these services in accordance with the regulation applied - e.g. free market driven or restricted to certain areas - should also be further explored.

\section{ACKNOWLEDGMENT}

This study was supported by SEAT, S.A., CARNET and Generalitat de Catalunya (AGAUR) [2016 DI 023].

\section{REFERENCES}

[1] Bonazzi, R. \& Pigneur, Y., The Hitchhiker's Guide to the Galaxy of Dynamic Ridesharing, pp. 1207-1216, 2015.

[2] Gao, S. \& Zhang, X., Understanding business models in the sharing economy in China: A case study. Social Media: The Good, the Bad, and the Ugly, 9844, pp. 661-672, 2016.

[3] Watanabe, C. Naveed, K. \& Neittaanmäki, P., Co-evolution of three mega-trends nurtures un-captured GDP - Uber's ride-sharing revolution. Technology and Society, 46, pp. 164-185, 2016.

[4] Janasz, T. \& Schneidewind, U., The future of automobility. Shaping the Digital Enterprise, eds. G. Oswald \& M. Kleinemeier, Springer International Publishing: Cham, pp. 253-285, 2017.

[5] Alonso-Mora, J. Samaranayake, S. Wallar, A. Frazzoli, E. \& Rus, D., On-demand highcapacity ride-sharing via dynamic trip-vehicle assignment. Proceedings of the National academy of Sciences, 114(3), pp. 462-467, 2017.

[6] Oxford Mail, "Uber for buses" could pick you up anywhere in east of Oxford in under 10 minutes. Oxford Mail, 11-May-2018. [Online], available at http://www. oxfordmail.co.uk/news/16219236.New___Uber_for_buses__could_pick_you_up_ from_home_in_under_10_minutes/, 2018 (accessed 20 May 2018).

[7] Guerrero, D., Barcelona restringirá la circulación de los vehículos más contaminantes de forma permanente a partir de 2020. La Vanguardia, 21 November 2016. [Online], available at http://www.lavanguardia.com/local/barcelona/20161121/412028354146/barcelona-restricciones-coches-mas-contaminantes-2020.html, 2016 (accessed 09 March 2017).

[8] IERMB, Workday Mobility Survey in the RMB, 2017, 2018.

[9] Barcelona City Council, Traffic volume at the entrances to the city. 2011-2015. Statistical yearbook of Barcelona city. Year 2016, 2016. [Online], available at http://www.bcn. cat/estadistica/angles/dades/anuari/cap15/C1511010.htm, 2016 (accessed 08 August 2017).

[10] Gilibert, M. Ribas, I. \& Rodriguez-Donaire, S., Analysis of mobility patterns and intended use of shared mobility services in the Barcelona region. Presented at the European Transport Conference 2017, Barcelona, 2017.

[11] Uber, Uber - Earn Money by Driving or Get a Ride Now, 2017. [Online], available at https://www.uber.com/es-ES/, 2017 (accessed 07 July 2017).

[12] CleverShuttle, 'CleverShuttle I RidePooling-Fahrdienst - Pay Less. Move Green. CleverShuttle | RidePooling-Fahrdienst, 2018. [Online], available at https://www.clevershuttle.de/, 2018 (accessed 27 August 2018). 
[13] Via, Smarter shared rides, 2018. [Online], available at https://ridewithvia.com/, 2018 (accessed: 20 May 2018).

[14] Lyft, Ride with Lyft. Ride with Lyft, 2018. [Online], available at https://www.lyft.com/ rider, 2018 (accessed: 26 Nov 2018).

[15] Didi Chuxing, Didi Chuxing. Didi Chuxing, 2018. [Online], available at http://www. didichuxing.com/en/, 2018 (accessed 20 May 2018).

[16] Osterwalder, A. Pigneur, Y. \& Tucci, C.L., Clarifying business models: Origins, present, and future of the concept. Communications of the Association for Information Systems, 15, May 2005.

[17] Yin, R.K., Case study research : design and methods, 3rd ed., SAGE Publications: Thousand Oaks, California, 2013.

[18] Watanabe, C. Naveed, K. Neittaanmäki, P. \& Fox, B., Consolidated challenge to social demand for resilient platforms - Lessons from Uber's global expansion. Technology and Society, 48, pp. 33-53, 2017.

[19] $\mathrm{Wu}, \mathrm{L} .$, Understanding collaborative consumption business model: Case of car sharing systems. Presented at the international conference on materials, manufacturing and mechanical engineering (MMME 2016), Beijing, vol. DEStech, pp. 403-409, 2016.

[20] Gilibert, M. Ribas, I. \& Rodriguez-Donaire, S., Study of commuting on-demand shared ride-hailing services: results from a case study in Barcelona. WIT Transactions Built Environment, 182, WIT Press, 2019. 